\title{
The Long-Term Impact of Covid-19 On Presentations To A Specialist Child \& Adolescent Eating Disorder Program
}

\section{Sally Campbell}

University College Dublin

Kristen Maunder ( $\nabla$ kmaunder@me.com )

University College Dublin

Oonagh Lehmann

Lucena Clinic, St. John of God Community Services

\section{Mark McKeown}

Lucena Clinic, St. John of God Community Services

\section{Fiona McNicholas}

University College Dublin

\section{Research Article}

Keywords:

Posted Date: January 18th, 2022

DOI: https://doi.org/10.21203/rs.3.rs-1236019/v1

License: (c) (i) This work is licensed under a Creative Commons Attribution 4.0 International License. Read Full License 


\section{Abstract}

Background: Concern has been expressed about an increase in mental illness and eating disorders in particular during the pandemic. Whether Covid-19 associated stress presents a specific risk for eating disorders, new or relapsing, in vulnerable groups remains to be established.

Aim: This study explores any impact of Covid-19 on numbers and clinical profile of eating disorder presentations to a Child and Adolescent Mental Health Service (CAMHS) specialist eating disorder treatment program pre and during Covid-19.

Methods: Following ethical approval, retrospective data extraction from electronic healthcare records from all referrals to a CAMHS specialist eating disorder treatment program in Dublin, Ireland was conducted. The study period covered 42 months, from $1^{\text {st }}$ January 2018 until $31^{\text {st }}$ Aug 2021 . Referral rates and clinical characteristics of pre- Covid-19 (January 2018-Feb 2020) and Covid-19 patients (March 2020Aug 2021) were examined, using Welch's t- and chi-square tests for continuous and categorical data respectively.

Results: 128 youth were assessed over the 42-month study period, with significantly higher rates of referrals post-pandemic (3.78 per month compared to a pre- Covid-19 rate of $2.31 /$ month). $(p=.02)$. Youth referred during Covid-19 lost weight at a faster rate; $2.3 \mathrm{~kg} / \mathrm{month}$ compared to $1.9 \mathrm{~kg} / \mathrm{month}$ pre- Covid-19 $(p=.39)$ and showed a higher rate of \% Ideal bodyweight loss (IBW), $4.8 \%$ IBW/month compared to $2.6 \%$ IBW/month pre- Covid-19 $(\mathrm{p}=<.001)$. They also had a shorter duration of illness pre-referral $(M=7.4$ months, $S D=3$ pre-Covid-19; $M=4.8$ months, $S D=4.5$ post Covid-19, $(p<.001)$, with fewer youth $(19 \%)$ prescribed psychotropic medication than pre Covid-19 (43\%, $p=.011)$. Many youth $(80 \%)$ self-declared Covid-19 as having had an adverse effect on their overall well-being and as a contributory factor to the development of their eating disordered pathology.

Conclusions: This study supports the growing consensus of a Covid-19 specific impact for ED services with higher rates of referrals, youth presenting with a faster pace of IBW\% loss and earlier referral to specialist services. Whether this reflects a true and specific increase in EDs or reflects an overall increase in CAMHS referrals, with increased transfer to ED services, needs further examination.

\section{Plain English Summary}

Covid-19 pandemic and the associated public health restrictions has led to unprecedented changes in how we are living our lives at present. Youth have been disproportionately affected following school closures, social disconnection; family related stressors and that these have led to an increase in mental health distress and illness. Clinicians and researchers have also reported an increase in eating psychopathology, referring to a 'tsunami of eating disorders', with increased attendances at specialist clinics. Some researchers however have reported that health, exercise and relationship with food have improved for certain groups. 
This study examines this further, examining electronic health care records of all referrals to a specialist eating disorder service over a 42 month period, before and during Covid-19 (January 2018 -August 2021). This service covers $13 \%$ of all Irish youth.

This study found that the numbers of youth referred had increased during the pandemic, there was a faster rate of weight loss, fewer were on medication and they were referred earlier to specialist services. This increased demand on an already under resourced service is a concern. Health services must consider allocating more funding and staffing to ensure children and adolescents can access appropriate treatment in a timely fashion.

\section{Background}

Following the declaration by WHO in March 2020, ${ }^{[1]}$ of a Covid-19 global pandemic most countries imposed immediate and stringent restrictive contingency measures aimed at containing the virus. These have severely impacted the lives of children and adolescents, with closures of school, universities, restriction on usual sporting events, training and social gatherings and exposing youth to debilitating effects on educational, psychological and developmental attainment. ${ }^{[2]}$

A recent systematic review reported higher rates of depressive and anxious symptoms and an increased prevalence of suicidal ideation and non-suicidal self-injury during the pandemic compared to reported pre-pandemic rates. ${ }^{[3]}$ Other studies have drawn attention to vulnerable time periods with distress being magnified at times of lockdown. Countries with higher stringency measures had correspondingly higher negative impacts, and emergence of childhood pathology closely mirrored school opening and closing periods. ${ }^{[4]}$ However, not all studies suggest deteriorating mental health, which is suggestive of the considerable disparity in the results on the impact of the pandemic on the mental health of children and young people. Many studies have suggested adolescent age group and female gender to be disproportionately affected, possibly linked to the salience of social connectivity in this cohort. Large scale population surveys highlighted significant effects on eating and exercise behaviors, with deterioration in eating symptomatology in those with pre-existing ED. ${ }^{[5]}$ Given initial concerns about possible food shortages, and limits on the frequency of shopping trips to comply with travel restrictions, difficulties and anxieties about access to usual foods and avoidance of bulk buying were understandable in the context of those with a prior eating disorders (ED). Some suggested presentations in youth were with higher medical risk and more atypical symptoms. ${ }^{[6,7]}$

Although the causes of EDs remain complex, with biological, cultural and psychological components, personal control is proposed to play a central role in both etiology and maintenance. The pandemic, a period of tremendous uncertainty and self-perceived lack of control, could be particularly intolerable for a group of vulnerable youth and might account for the rise in ED referrals reported. The public health and media messaging, encouraging a healthy lifestyle approach to eating and exercise, might also have been triggering for some. The absence of usual distractions and mood boosting activities, such as sporting events, social contact and school attendances, might further have destabilized some youth. 
The objective of this study was to assess the impact of Covid-19 on a specialist ED program embedded in CAMHS. Specific aims were to i) to examine the rate of referrals pre- Covid-19_(January 2018-Feb 2020) compared to during the pandemic (March 2020-Aug 2021); and ii) to compare the clinical profile between time periods.

\section{Methods}

\section{Study Setting}

The ED specialist team offers assessment and if appropriate, treatment to youth with evidence of an ED. It is a government-funded public health service covering an urban area in Dublin, and responsible for provision of CAMHS to a population of 260,560 or $12.7 \%$ of all youth in the Republic of Ireland (ROI). The service runs one day per week with multi-disciplinary team input involving a consultant child and adolescent psychiatrist, community Mental Health $(\mathrm{MH})$ Nurses, clinical psychologists and social workers offering Family Based Treatment (FBT). ${ }^{[14]}$ Monthly access to a pediatrician and dietitian is also incorporated into treatment programs. Referrals to the specialist ED or FBT team are received from local CAMHS teams, who in turn have been referred cases either from general practitioners (GPS), or other health services.

\section{Study Population}

All FBT referrals from CAMHS of youth under 18 who were offered an initial assessment between Jan 2018 and August 2021 were included in the study.

\section{Data Collection}

Data was extracted from the electronic health record, using the service's Mental Health Information System (MHIS). Data was de-identified at source and transferred into an electronic data base for analysis, using Statistical Package for Social Sciences (SPSS) the study was approved by the Research Ethics Committee of Saint John of God Hospital Service Group (ID787 - June 2021)

\section{Statistical Analysis}

The study time periods were defined as pre-COVID-19 (January 2018-Feb 2020), a period of 26 months and during COVID-19 (March 2020-August 2021), a period of 18 months. Descriptive statistics were used to categorize the sample. Mean and standard deviations (SD) were used to describe age, duration of weight loss and anthropometric data. BMI is generally used to reflect degrees of nutrition among adults with an ED. However, given this varies as a function of age, the Ideal Body Weight (IBW), IBW\% and deviation from pre-morbid IBW\%, is used. Frequencies and percentages were used to describe sex, level of education, ED type, presence of psychiatric co-morbidities, psychotropic medication prescriptions, actions and thoughts of self-harm, and any inpatient admissions. Additionally, data was extracted for any case in which mention was made by the young person, parent or clinician as to a contributory impact of 
Covid-19 acting as a precipitating factor and presented in a quantitative fashion. Quantitative variables were compared using independent samples t-test. and categorical variables using Chi-squared tests. All analyses were performed using SPSS.

\section{Results}

128 cases were referred to the FBT during the study period, predominantly female (93\%), ranging in age from 9 to 17, with a mean age of 14.45 (SD 2) (Table 1). The majority were attending secondary school (88\%). Nearly all youth (93\%) referred had a diagnosis of Anorexia Nervosa (AN) made post ED specialist team assessment, with non -AN cases (7) all being referred post pandemic. The majority $(\mathrm{N}=101,78.9 \%)$ had at least one co-morbidity, most often a mood disorder ( $N=76,59 \%) .28$ patients (22\%) had selfharmed in the past and a similar number $(\mathrm{N}=35,27 \%)$ had thoughts of self-harm. At the initial assessment, the average IBW was $85.3 \%(S D=11.1)$ and premorbid IBW of $100.6 \%(S D=13.2)$. The average duration of illness pre-referral to FBT team was 6 months (SD 4.1). Forty (31\%) young people were on psychotropic medication, and $53(41 \%)$ of patients had a prior hospital admission for ED management.

Table 1. Referral characteristics to FBT pre- Covid-19 and during- Covid-19 


\begin{tabular}{|c|c|c|c|c|}
\hline & $\begin{array}{l}\text { Total } \\
\text { Sample }\end{array}$ & $\begin{array}{l}\text { Pre- Covid- } \\
19\end{array}$ & $\begin{array}{l}\text { During/post- } \\
\text { Covid- } 19\end{array}$ & $\begin{array}{l}\text { Significance (chi-square or } \\
\text { independent samples t-test) }\end{array}$ \\
\hline $\mathrm{N}(\%)$ & 128 & $65(51)$ & $63(49)$ & \\
\hline Referrals per month & 2.9 & 2.31 & 3.78 & .021 \\
\hline $\begin{array}{l}\text { Age years (mean } \pm \\
\text { SD) }\end{array}$ & $14.45(2)$ & $14.6(2.1)$ & $14.3(1.9)$ & .372 \\
\hline \multirow[t]{2}{*}{ Sex, N (\%) } & F: 102 (92) & $F: 60(92)$ & F: 59 (94) & .766 \\
\hline & M: 9 (8) & M: 5 (8) & M: 4 (6) & \\
\hline \multirow{2}{*}{$\begin{array}{l}\text { In primary or } \\
\text { secondary school, } \\
\mathrm{N}(\%)\end{array}$} & $\begin{array}{l}\text { Primary: } \\
16(13)\end{array}$ & $\begin{array}{l}\text { Primary: } \\
10(15)\end{array}$ & $\begin{array}{l}\text { Primary: } 6 \\
(10)\end{array}$ & .372 \\
\hline & $\begin{array}{l}\text { Secondary: } \\
112(88)\end{array}$ & $\begin{array}{l}\text { Secondary: } \\
55 \text { (85) }\end{array}$ & $\begin{array}{l}\text { Secondary: } \\
57(91)\end{array}$ & \\
\hline \multirow[t]{3}{*}{$\begin{array}{l}\text { Eating disorder type, } \\
\text { N (\%) }\end{array}$} & $\begin{array}{l}\text { AN: } 119 \\
\text { (93) }\end{array}$ & $\begin{array}{l}\text { AN: } 62 \\
(95)\end{array}$ & \multirow{3}{*}{$\begin{array}{l}\text { AN: } 57 \text { (91) } \\
\text { ARFID: } 3 \text { (5) } \\
\text { EDNOS: } 3 \\
\text { (5) }\end{array}$} & \multirow[t]{3}{*}{.634} \\
\hline & $\begin{array}{l}\text { ARFID: } 5 \\
\text { (4) }\end{array}$ & $\begin{array}{l}\text { ARFID: } 2 \\
(3)\end{array}$ & & \\
\hline & $\begin{array}{l}\text { EDNOS: } 4 \\
\text { (3) }\end{array}$ & $\begin{array}{l}\text { EDNOS: } 1 \\
\text { (2) }\end{array}$ & & \\
\hline Any co-morbidity, $n(\%)$ & $101(78.9)$ & $52(80)$ & $49(77.8)$ & .758 \\
\hline Mood disorder, N (\%) & $76(59)$ & $36(55)$ & $40(64)$ & .350 \\
\hline Anxiety disorder, N (\%) & $47(37)$ & $22(34)$ & $25(40)$ & .493 \\
\hline $\begin{array}{l}\text { Autism Spectrum } \\
\text { Disorder, N (\%) }\end{array}$ & $13(10)$ & $6(9)$ & $7(11)$ & .725 \\
\hline Other disorder, $\mathrm{N}$ (\%) & $16(13)$ & $11(17)$ & $5(8)$ & .124 \\
\hline $\begin{array}{l}\text { Any psychotropic } \\
\text { medication, } \mathrm{N}(\%)\end{array}$ & $40(31)$ & $28(43)$ & $12(19)$ & .011 \\
\hline $\begin{array}{l}\text { Actions of self-harm or } \\
\text { overdose, } \mathrm{N}(\%)\end{array}$ & $28(22)$ & $15(23)$ & $13(1)$ & .796 \\
\hline $\begin{array}{l}\text { Thoughts of self-harm } \\
\text { or overdose, } \mathrm{N}(\%)\end{array}$ & $35(27)$ & $21(32)$ & $14(22)$ & .349 \\
\hline $\begin{array}{l}\text { Prior inpatient } \\
\text { admission for ED, } \\
\mathrm{N}(\%)\end{array}$ & $53(41)$ & $30(45)$ & $26(37)$ & .163 \\
\hline
\end{tabular}


The clinical presentation of pre- Covid-19 patients $(n=65 ; 51 \%)$ were compared to the during Covid-19 patients $(n=63,49 \%)$ (Table 1$)$. Those referred post pandemic had higher rates of ASD (11\%) compared to $9 \%$ pre-Covid, although not significant $\left[x^{2}(1, n=95)=1.53, p=.725\right]$ (Table 1). Fewer post pandemic referred cases were on psychotropic medication ( $19 \%$ as opposed to $43 \%)\left[x^{2}(1, n=95)=2.73, p=.011\right]$. There was no difference in presence of self-harm, suicidal ideation or admission rates between groups (Table 1). With regard to premorbid IBW\%, there was no difference between groups ( $98 \%$ versus $103.5 \%$ ), or IBW\% at assessment (83.7\% versus $87 \%$ ) (Table 2$)$. The rate of weight loss during the pandemic was greater $(1.94 \mathrm{~kg} / \mathrm{month}$ compared to $2.3 \mathrm{~kg} / \mathrm{m})$ but this was not significant $(\mathrm{t}(65)=2.878, \mathrm{p}=.395)$. However, the duration of illness pre-referral was significantly shorter in youth referred during Covid-19 (4.8 months compared to $7.4 ;(t(91)=2.151, p=.001)$. Furthermore, the rate of IBW\% loss/month was significantly great during Covid-19 $(4.8 \%$ month compared to $2.6 ;(t)(91)=2.151, p=.001)$.

Table 2. Anthropometric characteristics pre-Covid-19 and during-Covid-19. 


\begin{tabular}{|c|c|c|c|c|}
\hline & $\begin{array}{l}\text { Total } \\
\text { Sample }\end{array}$ & $\begin{array}{l}\text { Pre- } \\
\text { Covid- } \\
19\end{array}$ & $\begin{array}{l}\text { During/post- } \\
\text { Covid-19 }\end{array}$ & $\begin{array}{l}\text { Significance } \\
\text { (independent } \\
\text { samples t-test) }\end{array}$ \\
\hline \multirow[t]{2}{*}{$\begin{array}{l}\text { Duration weight loss months pre referral, } \\
\text { months (mean } \pm \text { SD) }\end{array}$} & $\begin{array}{l}6.1 \\
(4.1)\end{array}$ & $\begin{array}{l}7.4 \\
(4.5)\end{array}$ & $4.8(3)$ & \multirow[t]{2}{*}{$<.001$} \\
\hline & $\mathrm{N}: 108$ & $\mathrm{~N}: 62$ & $\mathrm{~N}: 54$ & \\
\hline \multirow[t]{2}{*}{ Premorbid IBW \% (mean \pm SD) } & $\begin{array}{l}100.6 \\
(13.2)\end{array}$ & $\begin{array}{l}98 \\
(12)\end{array}$ & \multirow{2}{*}{$\mathrm{N}: 63$} & \multirow[t]{2}{*}{.120} \\
\hline & $\mathrm{N}: 128$ & $\mathrm{~N}: 65$ & & \\
\hline IBW\% at FBT assessment $\%($ mean \pm SD $)$ & $\mathrm{N}: 128$ & $\mathrm{~N}: 65$ & $\mathrm{~N}: 63$ & .100 \\
\hline \multirow[t]{2}{*}{$\begin{array}{l}\text { Difference in IBW\% (from premorbid to } \\
\text { assessment) \% (mean } \pm \text { SD) }\end{array}$} & $\begin{array}{l}15.24 \\
(10.2)\end{array}$ & $\begin{array}{l}13.99 \\
(10.6)\end{array}$ & \multirow{2}{*}{$\begin{array}{l}16.5(9.5) \\
\mathrm{N}: 63\end{array}$} & \multirow[t]{2}{*}{.159} \\
\hline & $\mathrm{N}: 128$ & $\mathrm{~N}: 65$ & & \\
\hline \multirow[t]{2}{*}{ Rate change in IBW\% / month (mean \pm SD) } & $\begin{array}{l}3.7 \\
(3.5)\end{array}$ & $\begin{array}{l}2.6 \\
(3)\end{array}$ & \multirow{2}{*}{$\begin{array}{l}4.8(3.6) \\
N: 63\end{array}$} & \multirow[t]{2}{*}{$<.001$} \\
\hline & $\mathrm{N}: 125$ & $\mathrm{~N}: 62$ & & \\
\hline \multirow[t]{2}{*}{$\begin{array}{l}\text { Weight loss from premorbid weight to } \\
\text { assessment weight kg (mean } \pm \text { SD) }\end{array}$} & $\begin{array}{l}8.6 \\
(5.4)\end{array}$ & $\begin{array}{l}9.13 \\
(7.2)\end{array}$ & \multirow{2}{*}{$\begin{array}{l}8.35(4.5) \\
N: 54\end{array}$} & \multirow[t]{2}{*}{.625} \\
\hline & $\mathrm{N}: 79$ & $\mathrm{~N}: 25$ & & \\
\hline \multirow[t]{2}{*}{$\begin{array}{l}\text { Weight loss from premorbid weight to } \\
\text { assessment weight } \mathrm{kg} / \text { month (mean } \pm \mathrm{SD} \text { ) }\end{array}$} & $\begin{array}{l}2.2 \\
(1.8)\end{array}$ & $\begin{array}{l}1.94 \\
(2.3)\end{array}$ & & \multirow[t]{2}{*}{.395} \\
\hline & N: 78 & $\mathrm{~N}: 24$ & $\mathrm{~N}: 54$ & \\
\hline
\end{tabular}

Significantly more referrals were received in the 18 months during the pandemic, with a rate of 3.78 per month compared to a pre-Covid-19 rate of 2.31 per month $(p=.021)($ Graph 1) 
Of cases referred during Covid-19, mention was made in the clinical notes of Covid-19 having had a significant negative effect on the young person in 58 (82.9\%). In 49 cases $(70 \%)$ entries recorded a perceived 'significant' adverse impact. Specific clinical entries related to the impact of lockdown restrictions on social contact and general activities $(32,45.7 \%)$ and an initial adoption of a focus on exercise and healthy eating as a coping strategy $(9,12.9 \%)$. School related anxieties (3) and health anxieties regarding possible infection with Covid-19 (5) were less commonly cited. Over a fifth of preCovid-19 cases regressed during- Covid-19, but three youth, already in treatment at the start of Covid-19, reported an improvement during Covid-19, describing less social pressure, and reduced social comparisons due to restrictions on social contact.

\section{Discussion}

This review of referrals over a 3 year period to a specialist community ED treatment service confirms what is already known about eating disorders, in terms of the occurrence typically having a female predominance, occurring in an adolescent age and presenting with low ideal body weight \%. However, the review signals an increase in presentation during Covid-19, and a suggestion that clinical presentations are somewhat different. Monthly referral rates were significantly higher, almost double the rate of the prepandemic period (3.9 compared to 2.3), referrals made from CAMHS were following a shorter duration of illness (4.9 months compared to 7.6). Referrals did not differ in terms of pre-morbid (104\% versus $100 \%)$ or IBW\% at assessment (87\% versus $83 \%$ ), but there was a significantly greater speed of IBW\% loss (4.8\% compared to $2.6 \%$ ). Significantly fewer youth during-Covid-19 onset were on any psychotropic medications ( $23 \%$ post during the pandemic compared to $41 \%$ before). Although there were slightly more youth during Covid-19 who were diagnosed with an eating disorder other than Anorexia Nervosa, had an additional comorbid mental illness, and a diagnosis of ASD, these did not reach statistical.

A similar study, a retrospective case note review of referrals to a pediatric tertiary ED treatment program in Canada ( $\mathrm{N}=48$ ) covering a 7 month period (April-October 2020) examined the impact of Covid-19 on clinical profile ${ }^{[8]} .40 \%$ of their sample were considered to have their ED triggered by the pandemic. They found a higher rate of medical instability in Covid-19 triggered cases (79\% versus 55\%) and when IBW\% was compared with 2019, youth presenting during the pandemic had lower IBW\%s, higher self-reported impairment and were medically more unstable ${ }^{[6]}$ Although Spettigue and colleagues did not report on the monthly rates of presentation, other studies have reported an increase in ED referrals. Admissions to a pediatric hospital in the Republic of Ireland (ROI) increased by $66 \%$ during the early period of the pandemic, with a suggestion by the authors of lower IBW\% and increased medical instability. ${ }^{[6]}$ The National Psychiatric In-Patient Reporting System (NPIRS) in ROI showed a 32\% overall increase in hospital admissions for adults with an ED and an increase of 51\% for youth when comparing 2019 and $2020^{[9]}$. Pediatric presentations in other countries have also increased, leading concerned clinicians to refer to a 'tsunami' or 'an outbreak of AN admissions' following a $104 \%$ increase in referrals. ${ }^{[10,11]}$ 
It has also been found that as the pandemic has continued, the relative risk of eating disorders has increased. Reviewing electronic health records of 5.2 million cases, mainly from USA, Taquet and colleagues found a small but significant increased incidence of $15.3 \%$ new onset Anorexia Nervosa in those aged $10-30^{[12]}$. These were predominantly female (78.1\%) and adolescent age (mean age 16.2yrs). ${ }^{[12]}$ Moreover, new onset AN cases during Covid-19 had an increased risk of having made a suicide attempt or having suicidal ideation compared to cases diagnosed in the previous 3 years. This offers some support to this study, and that of others, suggesting atypicality in clinical presentation. ${ }^{[7]}$

Fear was expressed early on about the impact of 'stay at home' orders and lockdowns on help-seeking hesitancy and lack of access to services. Although there was a successful compensatory move to telepsychiatry, limited access of face to face services for youth where medical reviews constitute an important part of treatment monitoring was a concern, ${ }^{[13]}$ and might have contributed to delayed help seeking, lower IBW\% and account in part for the increased emergency department attendances ${ }^{[6]}$ The increased number of referrals, and shorter time to refer to the FBT team might reflect a true increase of more clinically sinister eating pathology, during Covid-19, or might reflect an increased onward referral from generic CAMHS exposed to unmanageable demand. Data collected from the CAMHS linked to the FBT team saw a dramatic 50\% increase in both routine and urgent referrals from September 2020 compared to previous years (2018/2019), with the highest increase in November 2020 (180\%). ${ }^{[14]}$ Clinic activity also increased from September 2020, with double the number of out-patient appointments offered compared to previous years and significantly lower rates of non-attendance. ${ }^{[14]}$ This increased CAMHS demand might have triggered increased FBT referrals.

Early on in the pandemic, public health advice regarding health promotion was offered as adaptive coping strategies during lockdown, with a focus on healthier eating, regular exercise, and increasing quality time with family by cooking and eating. Phillipou et al examined changes in eating and exercise behaviors during the Covid-19 pandemic ${ }^{[5]}$. Of the 5469 responders, 180 self-identified as having a past or current ED, mainly AN. Increase in food restriction and binge eating were reported by respondents with an ED history (67.1\% and $20.5 \%$ ) compared to (27.6\%). Increased purging (18.2\%) and exercise (48.9\%) was also noted in the ED cohort. Approximately one third of the general population sample $(34.8 \%)$ reported more exercise while almost half $(43.4 \%)$ reported reduced exercise following the onset of the pandemic ${ }^{[5]}$ The findings of this study highlight the varied nature of eating and exercise responses during the pandemic, and suggest a more deleterious effect in those already at risk. ${ }^{[5]}$ Other studies have suggested eating and exercise being used as positive coping strategies. In one study, $40 \%$ of children cited exercise as a positive coping strategy, and $25 \%$ reported an increase in consumption of healthy foods during Covid-19. ${ }^{[15]}$ It is possible, and reported, that initial adaptive coping strategies may become excessive over time, and lead to engagement in excessive exercise regimes, calorie counting, or restrictive eating. ${ }^{[7]}$ Deschasaux-Tanguy and colleagues also reported on mixed changes in diet and physical activity with half $(52.8 \%)$ of their sample reporting a decrease in physical activity, early weight gain reported by a third (35\%) while weight loss was reported by almost a quarter $(23 \%) .{ }^{[16]}$ 
The extent and nature of psychological difficulties in youth during Covid-19 is complex, mixed and unequal ${ }^{[17]}$ In the current study, many youth (80\%) self-declared Covid-19 as having had an adverse effect on their overall wellbeing and this was viewed as contributory to their ED pathology. Reduced peer support, school attendance, and inability to engage in usual sporting and academic endeavors were reported by youth to have contributed to increased anxiety and low mood, prompting self-doubt and poor self-image, including body dissatisfaction. Periods at home, in unstructured settings offered an easy opportunity to be exposed to food, and to engage in binge-purge cycles and to over indulge in exercise routines. However, 3 youth felt that their pre-existing eating disorders had improved, linked to reduced peer and academic pressure, increased parental meal supervision and an overall increase in family quality time. Further research is warranted investigating how the pandemic may both positively and negatively impact the psychological functioning of children and adolescents and the nature by which food and exercise are used to cope with adversity.

\section{Limitations}

It remains unclear whether the spike in referrals witnessed during Covid-19 reflect new onset psychopathology or exacerbations of symptoms in groups already at greater risk. This study is limited by the gate keeping nature of CAMHS, who may have their own reasons to refer or not. Whether referrals to the specialist ED program reflect changes in prevalence and clinical presentation, driven by an increased awareness by clinicians, such as general practitioners, or parents spending more time at home, as to possible ED psychopathology, or reflective of increased workloads on CAMHS needs further examination. The study is limited by the subjective unstructured nature in which the impact of Covid-19 was gathered. Despite these limitations, to the authors' knowledge this is the first study to describe in detail patterns of referrals to a specialist ED clinic over a 3-and-a-half-year period, allowing comparison of pre and postCovid-19 time periods. The study's relatively small sample size limits statistical power. Given the specialist nature of the study's ED service, the results may also not be generalizable to youth with EDs being treated in CAMHS.

\section{Conclusion}

Lockdown restrictions during the pandemic may have triggered typical and atypical EDs in young people. Youth with EDs referred to a specialist ED program during the Covid-19 pandemic exhibited a shorter duration of illness but faster rate of \% ideal body weight loss. The clinical presentation differed with significantly fewer youth prescribed psychotropic medication and a trend for increased comorbidity. Given their shorter duration of illness, youth with EDs referred during the pandemic may achieve improved outcomes with appropriate treatment. Health services should mobilize funds to ensure adequate access to ED assessment and appropriate treatment. Further research is required to better understand the effects of the Covid-19 pandemic on ED onset, presentation and trajectory amongst children and adolescents. Health promotion campaigns also need to be evaluated to limit any unintended consequences and to ensure a balance between adaptive and maladaptive responses. 


\section{Abbreviations}

AN: anorexia nervosa, ASD: autistic spectrum disorder, CAMHS: child and adolescent mental health service, ED: eating disorder, FBT family based treatment , IBW ideal body weight, MHIS: Mental Health Information System, ROI: Republic of Ireland SD standard deviation

\section{Declarations}

Acknowledgements

The authors wish to express gratitude to families and the FBT team for their flexibility with services during this busy period.

Author's contributions

All contributors have met the criteria recommended by the ICMJE. FMcN conceived and designed the study, SC took the lead in data collection, with assistance from $\mathrm{OL}, \mathrm{MMcK}$ and $\mathrm{KM}$ and under supervision of FMcN. SC wrote the initial draft of the manuscript, all authors (SC, KM, OL, MMcK, FMcN) subsequently reviewed and contributed to subsequent iterations of the paper. All authors consent to publication.

Funding

No funding has been received for the conduct of this study,

Supporting data and availability of data and materials

The anonymous data set is held with the $\mathrm{PI}, \mathrm{FMcN}$. Any request to access the data should be made to fiona.mcnicholas@ucd.ie and will be considered, subject to ethical guidance. Clinical material for the FBT team is also available.

Ethical Approval: The study was approved by the Research Ethics Committee of Saint John of God Hospital Service Group (ID787 - June 2021)

Consent for publication

An Ethics waiver of informed consent was received as the data was de-identified at source by study team personnel and transferred into an electronic data base for analysis.

Competing interests

The author, SC, KM, OL, MMcK, FMcN have no competing interests to declare.

\section{References}


1. World Health Organization. Statement on the second meeting of the International Health Regulations (2005) Emergency Committee regarding the outbreak of novel coronavirus: World Health Organization; 2020. Available from: https://www.who.int/news/item/30-01-2020-statement-on- thesecond-meeting-of-the-international-health-regulations-(2005)- emergency-committee-regarding-theoutbreak-of-novel-coronavirus-(2019-ncov)

2. Shweta Singh, Deblina Roy, Krittka Sinha, Sheeba Parveen, Ginni Sharma, Gunjan Joshi. Impact of COVID-19 and lockdown on mental health of children and adolescents: A narrative review with recommendations. Psychiatry Research Volume 293, Nov 2020

3. Hasina Samji, Judy Wu, Amilya Ladak, Cralyn Vossen, Eveyln Stewart, Naomi Dove et al. Review: Mental health impacts of the covid-19 pandemic on children and youth - a systematic review. Child and Adolescent Mental Health. 2021 Aug https://doi-org.ucd.idm.oclc.org/10.1111/camh.12501

4. Armbruster S, Klotzbücher V. Lost in lockdown? Covid-19, social distancing, and mental health in Germany. Diskussionsbeiträge; 2020.

5. Phillipou A, Meyer D, Neill E, Tan EJ, Toh WL, Van Rheenen TE et al. Eating and exercise behaviors in eating disorders and the general population during the COVID-19 pandemic in Australia: Initial results from the COLLATE project. International Journal of Eating Disorders. 2020 Jun 1.

6. Barrett E, Richardson SC. Eating Disorders During the COVID-19 Pandemic. Ir Med J. 2020;114(1):233.

7. McNicholas, F. Childhood onset exercise addiction or atypical anorexia nervosa during Covid-19: case report. Journal Of Eating Disorders, 2021. doi: 10.1186/s40337-021-00450-4

8. Spettigue W, Obeid N, Erbach M, Feder S, Finner N, Harrison ME, Isserlin L, Robinson A, Norris ML. The impact of COVID-19 on adolescents with eating disorders: a cohort study. Journal of Eating Disorders. 2021 Dec;9(1):1-8.

9. https://www.hrb.ie/publications/publication/activities-of-irish-psychiatric-units-and-hospitals2020/returnPage/1/Marsh S. Doctors warn of 'tsunami' of pandemic eating disorders. The Guardian. https://www.theguardian.com/society/2021/feb/11/doctors-warn-of-tsunami-of-pandemic-eatingdisorders (2021). Accessed 12 Apr 2021.

10. Marsh S. Doctors warn of 'tsunami' of pandemic eating disorders. The Guardian. https://www.theguardian.com/society/2021/feb/11/doctors-warn-of-tsunami-of-pandemic-eatingdisorders (2021). Accessed 12 Apr 2021.

11. Leask A. Covid 19 coronavirus: "Tsunami" of child eating disorders emerging after lockdowns in New Zealand. New Zealand Herald. https://www.nzherald.co.nz/nz/covid-19-coronavirus-tsunami-ofchild-eating-disorders-emerging-after-lockdowns-in-newzealand/M3ZHGQ4ICG72OUMRMFDOLN25CY/ (2021). Accessed 7 Apr 2021.

12. Taquet M, Geddes JR, Luciano S, Harrison PJ. Incidence and outcomes of eating disorders during the COVID-19 pandemic. The British Journal of Psychiatry. 2021 Jul 27:1-3.

13. Walsh O, McNicholas F. Assessment and management of anorexia nervosa during COVID-19. Irish Journal of Psychological Medicine. 2020 Sep;37(3):187-91. 
14. McNicholas F, Kelleher I, Hedderman E, Lynch F, Healy E, Thornton T, Barry E, Kelly L, McDonald J, Holmes K, Kavanagh G. Referral patterns for specialist child and adolescent mental health services in the Republic of Ireland during the COVID-19 pandemic compared with 2019 and 2018. BJPsych Open. 2021 May;7(3).

15. Alamrawy, R., Fadl, N., \& Khaled, A.. Psychiatric morbidity and dietary habits during COVID-19 pandemic: a cross-sectional study among Egyptian Youth (14-24 years). Middle East Current Psychiatry, 2021. 28(1). doi: 10.1186/s43045-021-00085-w

16. Deschasaux-Tanguy M, Druesne-Pecollo N, Esseddik Y, de Edelenyi FS, Allès B, Andreeva VA, Baudry J, Charreire H, Deschamps V, Egnell M, Fezeu LK. Diet and physical activity during the coronavirus disease 2019 (COVID-19) lockdown (March-May 2020): results from the French NutriNet-Santé cohort study. The American journal of clinical nutrition. 2021 Apr;113(4):924-38.

17. O'Reilly, A., Tibbs, M., Booth, A., Doyle, E., McKeague, B., \& Moore, J. A rapid review investigating the potential impact of a pandemic on the mental health of young people aged 12-25 years. Irish Journal Of Psychological Medicine, 2020. 38(3), 192-207. doi: 10.1017/ipm.2020.106

\section{Figures}

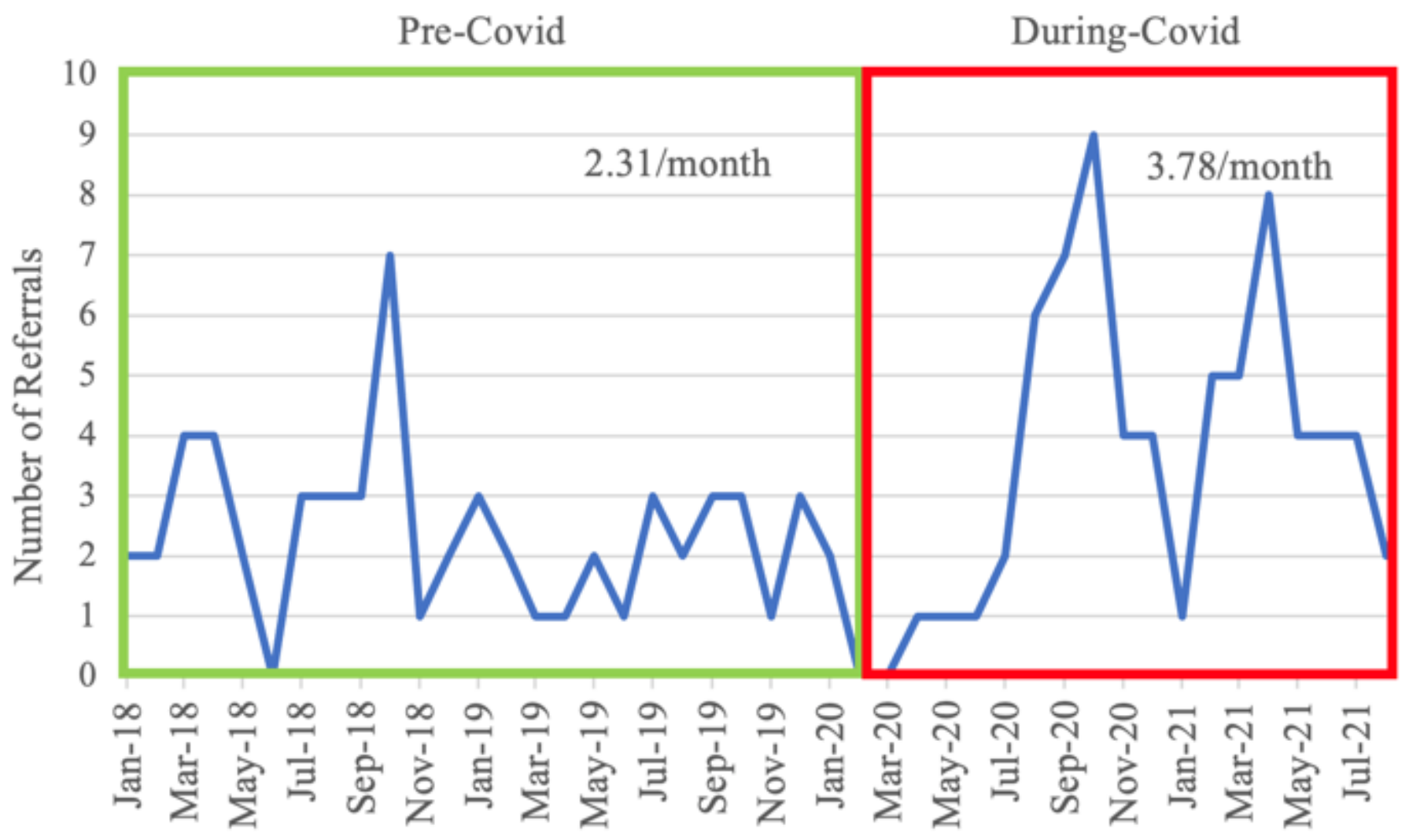

\section{Figure 1}

Number of FBT referrals from January 2018-August 2021. 


\section{Supplementary Files}

This is a list of supplementary files associated with this preprint. Click to download.

- Appendix1.docx 